\title{
AVALIAÇÃO E MELHORIA DA EXPERIÊNCIA DE USO DO SISTEMA INTEGRADO DE BUSCA DAS BIBLIOTECAS MUNICIPAIS DE SÃO PAULO
}

\author{
EVALUATION AND IMPROVEMENT OF THE EXPERIENCE OF USING THE \\ INTEGRATED SEARCH SYSTEM OF THE MUNICIPAL LIBRARIES OF SÃO \\ PAULO
}

\author{
Graciela Tocchetto ${ }^{1}$, Esp. \\ Ricardo Couto ${ }^{2}$, M.Sc.
}

(1) Faculdade Impacta Tecnologia

e-mail:graciela@tocchetto.com

(2) USP

e-mail: couto.ricardo@gmail.com

Usabilidade, experiência do usuário, biblioteca

O sistema de busca das bibliotecas municipais de São Paulo é uma das primeiras interações entre o usuário e o acervo. Os métodos utilizados nesse trabalho foram: análise heurística, teste de usabilidade, análise de tarefa e mapa de navegação. As propostas de melhorias incluem nova arquitetura de informação e interface.

\section{Usability, user experience, library}

The integrated search system of the municipal libraries of São Paulo is one of the first interactions between the user and the collection of the municipal library. The research methods used were analysis heuristics, usability testing, task analysis and map navigation. The proposals of improvements include new information architecture and new interface.

\section{Introdução}

É cada vez mais frequente a preocupação com a experiência de uso de artefatos digitais. Parte disso, por estarmos vivendo um período onde o consumo está sendo reinventado. As pessoas estão se dando conta que não é preciso possuir bens que sejam seus e de uso exclusivo, a economia colaborativa está encontrando cada vez mais adeptos. Serviços de streaming de música e vídeos são os que mais se destacam nesse novo cenário.

As bibliotecas sempre fizeram parte da economia 


\section{$16^{\circ}$ \\ ERGODESIGN USIHC CINAHPA}

colaborativa com o compartilhamento de livros e documentos. Além de possibilitar o acesso à informação de forma gratuita, o que por si só já é uma grande ferramenta de inclusão social.

Nesse contexto, verificou-se a importância e a abrangência do sistema municipal de bibliotecas da cidade de São Paulo e como esse serviço poderia ser aprimorado. Levou-se em consideração uma das suas principais ferramentas de contato com os usuários, o sistema de busca de itens no catálogo eletrônico do SMB (Sistema Municipal de Bibliotecas).

\section{Justificativa}

O SMB da cidade de São Paulo é composto por 107 bibliotecas que "recebem cerca de quatro milhões de consultas por ano. Atualmente os acervos somam mais de cinco milhões de documentos." (SISTEMA... 2016)

No site da prefeitura é possível pesquisar no acervo de todas as bibliotecas que compõem o SMB. Essa plataforma de pesquisa ao catálogo online integrado é o objeto de estudo deste trabalho.

A possibilidade de pesquisar em diversas bibliotecas em apenas uma plataforma é uma grande vantagem para o usuário. Com acesso a essa informação, ele pode localizar a biblioteca que possui o documento de seu interesse e buscá-lo quando quiser.

A análise do sistema de busca integrada do SMB pretende avaliar sua usabilidade levando em conta conceitos de design de interação pois, de acordo com Preece, Rogers e Sharp (2005): "uma preocupação central do design de interação é desenvolver produtos interativos que sejam utilizáveis."

Além de focar na eficiência e produtividade na realização de tarefas, o design de interação está cada vez mais preocupado com a criação de sistemas que sejam satisfatórios, agradáveis, interessantes, úteis, motivadores, esteticamente apreciáveis etc. Esses conceitos estão ligados com a experiência que proporcionarão ao usuário e $16^{\circ}$ Ergodesign - Congresso Internacional de Ergonomia e Usabilidade de Interfaces Humano Tecnológica: Produto, Informações Ambientes Construídos e Transporte

$16^{\circ}$ USIHC - Congresso Internacional de Ergonomia e Usabilidade de Interfaces Humano Computador

CINAHPA | 2017 - Congresso Internacional de Ambientes Hipermídia para Aprendizagem. como o usuário se sentirá na interação com o sistema (PREECE; ROGERS; SHARP, 2005).

O usuário deve ser sempre o foco no desenvolvimento de produtos. Conhecer esse usuário é essencial para entender suas necessidades e conseguir propor soluções para suas dores da melhor maneira possível. Esse projeto pretende conhecer os usuários do sistema integrado do SMB e realizar, junto com eles, a avaliação do atual sistema para assim propor melhorias que agreguem valor ao mesmo.

\section{Metodologia}

O problema a ser estudado no presente trabalho é: quais melhorias em termos de usabilidade podem ser feitas no sistema de busca integrado das bibliotecas municipais de São Paulo para que os usuários encontrem com mais facilidade os itens que desejam? Levando-se em consideração a hipótese de que os usuários têm dificuldades para encontrar alguns itens de seu interesse.

Para verificar a veracidade da hipótese acima proposta, este trabalho pretende utilizar métodos de pesquisa experimental e levantamento de dados com os usuários do sistema de busca. O plano experimental proposto utiliza o preenchimento do UX Canvas para conhecer melhor o produto em questão, mapa de navegação, análise de tarefas, análise heurística e pesquisa com usuários por meio de entrevistas e teste de usabilidade.

Para determinar os problemas e sugestões de melhoria no sistema decidiu-se utilizar diferentes técnicas de pesquisa, pois, de acordo com Preece, Rogers e Sharp (2005), métodos como "testes com usuários e a avaliação heurística geralmente revelam diferentes problemas de usabilidade".

\section{UX Canvas}

O preenchimento do canvas possibilita reunir dados essenciais sobre o negócio ou produto e dos usuários em um só lugar, ao mesmo tempo que aborda muitas das preocupações e ansiedades dos potenciais utilizadores (ZAWADZKI, 2016). Optou-se por usar o UX Canvas (Figura 1) 


\section{$16^{\circ}$ \\ ERGODESIGN USIHC CINAHPA}

elaborado por Alina Prelicz e Leszek Zawadzki. A análise foi feita pensando no produto já existente e também depois das melhorias que serão propostas no decorrer desse projeto.

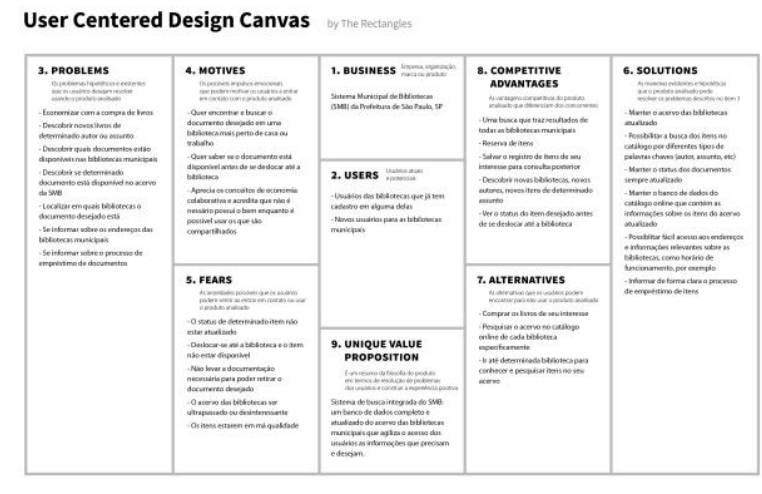

Figura 1: UX Canvas. Acesse a imagem maior aqui.

\section{Pesquisa e análise}

\subsection{Mapa de navegação - DoGo Map}

O mapa DoGo é um método ágil. É uma ferramenta que fornece perspectiva sobre o sistema global combinado com a funcionalidade de cada página. Mistura-se a visão de um mapa do site, com o detalhe de um fluxograma para visualizar como um sistema se encaixa. (KEEFER, 2015)

O método consiste em analisar cada página do sistema listando os "input fields" (campos de entrada), as ações possíveis como "do" e os destinos possíveis como "go". Cada página é numerada e identificada nos itens da lista "go". Além disso, há uma caixa exclusiva para campos comuns em todas as páginas, como no caso de menus (Figura 2). $16^{\circ}$ Ergodesign - Congresso Internacional de Ergonomia e Usabilidade de Interfaces Humano Tecnológica: Produto, Informações Ambientes Construídos e Transporte

$16^{\circ}$ USIHC - Congresso Internacional de Ergonomia e Usabilidade de Interfaces Humano Computador

CINAHPA | 2017 - Congresso Internacional de Ambientes Hipermídia para Aprendizagem.

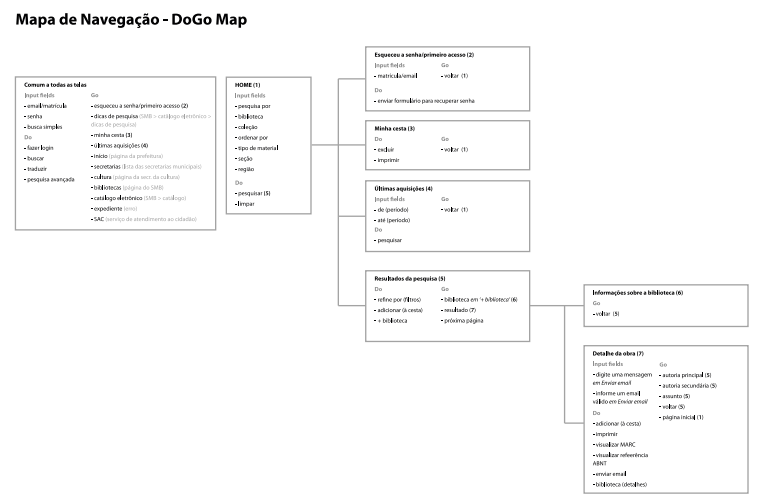

Figura 2: Mapa de navegação DoGo. Acesse o mapa maior aqui.

\subsection{Análise de tarefas}

A análise de tarefas é um detalhamento das informações e ações necessárias para que o usuário complete uma tarefa. Este documento ajuda designers e desenvolvedores a entenderem o sistema atual e como a informação transita dentro dele. (TEIXEIRA, 2016)

A tarefa analisada foi encontrar um livro disponível para empréstimo no sistema de buscas do ponto de vista de um usuário que já tenha familiaridade com o sistema (Figura 3).

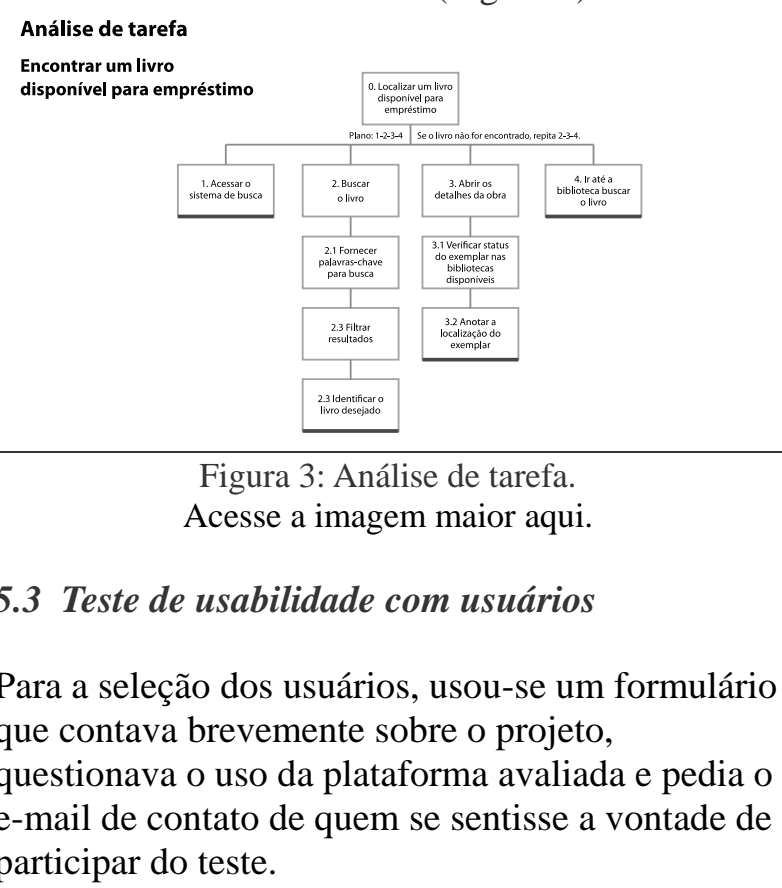

Realização:

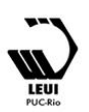




\section{$16^{\circ}$ \\ ERGODESIGN USIHC CINAHPA}

Esse formulário foi publicado em um grupo de leitores e um grupo interessado no mercado editorial no Facebook. Foram obtidas 14 respostas, sendo que 5 destes deixaram seu contato para participar do teste de usabilidade.

O teste de usabilidade é um processo no qual participantes representativos avaliam o grau que um produto se encontra em relação a critérios específicos de usabilidade (RUBIN, 1994).

De acordo com Preece, Rogers e Sharp (2005), o objetivo do teste consiste em responder a uma questão ou hipótese a fim de se descobrir uma informação nova. Além disso, o teste de usabilidade envolve registrar dados utilizando uma combinação de vídeo e registros da interação, questionários de satisfação e também entrevista.

Para esse trabalho, definiu-se o uso da entrevista semi-estruturada durante o teste de usabilidade. Trata-se de uma conversa com os usuários que possui questões abertas e fechadas, mesclando características das entrevistas estruturada e nãoestruturada (ALCÂNTARA, 2013). Para isso, elaborou-se um roteiro de teste a ser seguido levando em consideração o objetivo da pesquisa.

O roteiro foi dividido em três fases: questionário pré-uso do sistema, proposição de atividades e questionário pós-uso do sistema. Objetivos a serem atingidos com o teste: conhecer os usuários que usam o sistema; entender a percepção desses usuários ao utilizar o sistema; ouvir quais são as dificuldades de uso do sistema reconhecidas pelos usuários.

Foram executados 3 testes presenciais e 2 testes de forma remota. Todos os participantes conseguiram executar as quatro atividades propostas. Eles já tinham experiência com a ferramenta e a usavam com certa frequência.

\subsection{Análise heurística}

A avaliação heurística (NIELSEN, 1995) é um método para descobrir os problemas de usabilidade em uma interface. Esse método implica em ter um $16^{\circ}$ Ergodesign - Congresso Internacional de Ergonomia e Usabilidade de Interfaces Humano Tecnológica: Produto, Informações Ambientes Construídos e Transporte

$16^{\circ}$ USIHC - Congresso Internacional de Ergonomia e Usabilidade de Interfaces Humano Computador

CINAHPA | 2017 - Congresso Internacional de Ambientes Hipermídia para Aprendizagem.

pequeno conjunto de avaliadores para examinar a interface e julgar sua conformidade com princípios de usabilidade já conhecidos, as heurísticas.

Neste projeto, foram convidados 2 avaliadores para colaborar na avaliação heurística da interface da busca integrada das bibliotecas municipais de São Paulo, além da autora deste artigo: Guilherme Gonzalez e Wesley Jonathan Marcolino, somando 3 avaliações.

Meta de avaliação: verificar se a interface atual é consistente e encontrar problemas de usabilidade no do sistema. Interface avaliada:

http://bibliotecacircula.prefeitura.sp.gov.br/pesquis a/

Para a avaliação heurística foram utilizadas as 10 heurísticas de Nielsen (1995). Para determinar a gravidade dos problemas encontrados também seguiu-se o padrão de Nielsen (1995).

\section{Análise de resultados}

Depois das três análises heurísticas foi possível observar 28 problemas descritos. Destes, quatro são identificados como gravidade 4 , nove como 3 , doze como 2 e três como gravidade 1 . Os problemas encontrados estão relacionados às seguintes heurísticas: H1 Visibilidade e feedback: 6 ocorrências; H3 Controle do usuário e liberdade: 1; H4 Consistência e padrões: 4; H5 Prevenção de erros: 3; H6 Reconhecimento em vez de memorização: 4; H7 Flexibilidade e eficiência de uso: 2; H8 Estética e design minimalista: 5; H9 Ajuda aos usuários a reconhecerem, diagnosticarem e recuperarem-se de erros: 1; H10 Ajuda e documentação: 2 ocorrências.

Já os problemas de uso encontrados com os testes com usuários foram: a) Não é clara a utilidade do botão "+ Bibliotecas". b) Os participantes não perceberam e/ou não usaram a opção para ordenar os resultados antes de efetuar a busca presente na caixa de pesquisa palavra. c) Ao efetuar as tarefas, os participantes perceberam que diversos resultados eram irrelevantes à pesquisa feita. $\mathrm{d}$ ) Nem sempre os autores mais prováveis dos títulos buscados aparecem na opção de filtro. e) Alguns 


\section{$16^{\circ}$ \\ ERGODESIGN USIHC CINAHPA}

usuários relataram que algumas buscas retornam sem resultados quando filtram por biblioteca ou região mesmo quando, segundo elas, essas bibliotecas possuem o livro em questão.

Algumas características de comportamento que pode-se verificar: a maioria utiliza o sistema em casa e na própria biblioteca. Uma das participantes não navegou entre as páginas, resolveu usar filtros ou refazer a busca quando o resultado que ela queria não estava na primeira página. Outro participante preferiu conferir as informações do livro proposto na tarefa em outro site e depois filtrar por editora na busca e comentou que normalmente faz suas buscas dessa forma.

Pontos fortes no sistema observado: todos os participantes conseguiram realizar as tarefas propostas. Não tiveram dúvida sobre como encontrar as informações da biblioteca onde o exemplar estava disponível. Os participantes mais experientes com relação ao mercado editorial filtraram por editora.

Sugestões dos participantes: a possibilidade de reordenar os resultados da busca. Os livros aparecerem nos resultados agrupados por título diminuiria a quantidade de resultados e deixaria a busca menos confusa. Opção de buscar por palavras exatas.

Com os testes com usuários e análise heurística foi possível perceber que o sistema de buscas integrado das bibliotecas municipais de São Paulo é eficaz, ou seja, cumpre sua função. Porém deixa a desejar em algumas questões da experiência do usuário como eficiência e maleabilidade, no sentido de permitir que os usuários realizem todas as tarefas da maneira que desejam.

\subsection{Personas}

Personas são documentos que descrevem típicos usuários-alvo. [...] Com pesquisas e descrições apropriadas, as personas podem ilustrar um quadro muito claro sobre quem está usando o site ou aplicação e, potencialmente, até mesmo como estão $16^{\circ}$ Ergodesign - Congresso Internacional de Ergonomia e Usabilidade de Interfaces Humano Tecnológica: Produto, Informações Ambientes Construídos e Transporte

$16^{\circ}$ USIHC - Congresso Internacional de Ergonomia e Usabilidade de Interfaces Humano Computador

CINAHPA | 2017 - Congresso Internacional de Ambientes Hipermídia para Aprendizagem.

O contexto em que esse sistema está inserido é o dos usuários das bibliotecas em geral. Levando em conta esses dados, foram elaboradas 3 personas (Figura 4) para este projeto a partir dos perfis identificados de usuários do SMB de São Paulo.

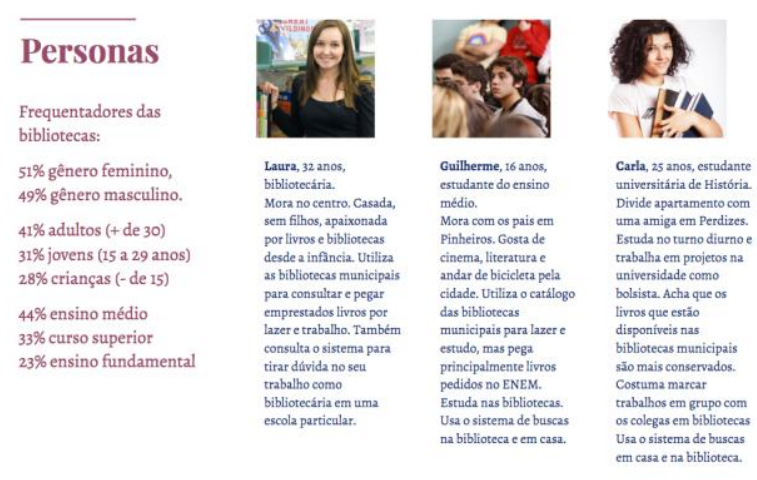

Figura 4: Personas. Acesse a imagem maior aqui.

Para as propostas de melhorias foram consideradas as necessidades dessas personas levando em consideração suas motivações e tipo de usos do sistema de busca.

\section{Propostas de melhorias}

Após a fase de pesquisa e análise dos resultados foi possível perceber diversas necessidades de melhorias para o sistema. Os pontos principais a serem melhorados observados foram os seguintes:

- Cabeçalho do site com excesso de informações podendo gerar confusão para os usuários (Figura 5).

- Duplicidade de opção de busca na tela inicial (Busca simples e Busca palavra).

- Busca avançada com opções que são ignoradas pelos usuários. Além de não ficar claro que a "Busca palavra" não é a busca avançada.

- Relevância dos resultados questionável e confusa. A opção para ordenar os resultados aparece antes da busca ser efetuada o que causa dificuldade de uso.

- O botão "+ bibliotecas" não é claro para os usuários, nem todos entendem sua função. 


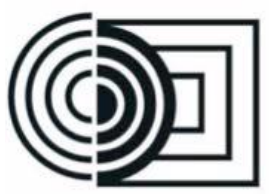

\section{$16^{\circ}$}

ERGODESIGN

USIHC CINAHPA $16^{\circ}$ Ergodesign - Congresso Internacional de Ergonomia e Usabilidade de Interfaces Humano Tecnológica: Produto, Informações Ambientes Construídos e Transporte

$16^{\circ}$ USIHC - Congresso Internacional de Ergonomia e Usabilidade de Interfaces Humano Computador

CINAHPA | 2017 - Congresso Internacional de Ambientes Hipermídia para Aprendizagem.

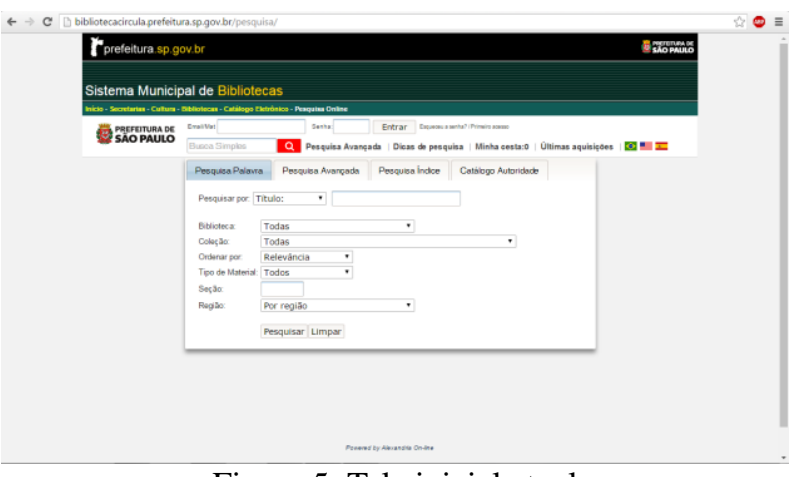

Figura 5: Tela inicial atual
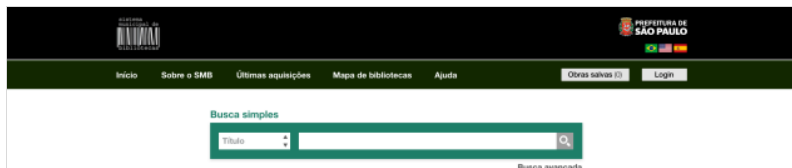

Figura 6: Proposta para tela inicial

Cabeçalho somente com informações relevantes sobre o sistema de busca (Figura 6). Links para outros sites da prefeitura no rodapé. Foco no campo de busca simples com opção para filtrar a palavra-chave por título, autor, editora, assunto, ISBN, ISSN ou todas opções. Campos para login dentro do botão "Login". Marca do SMB aplicada no cabeçalho do site.

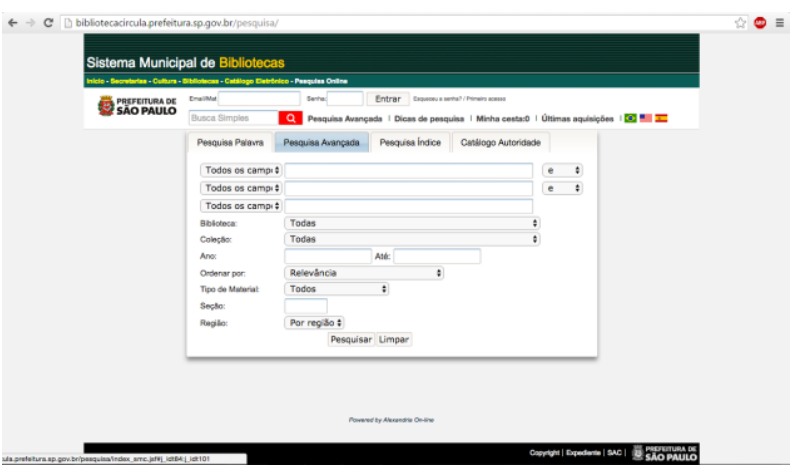

Figura 7: Tela de busca avançada atual

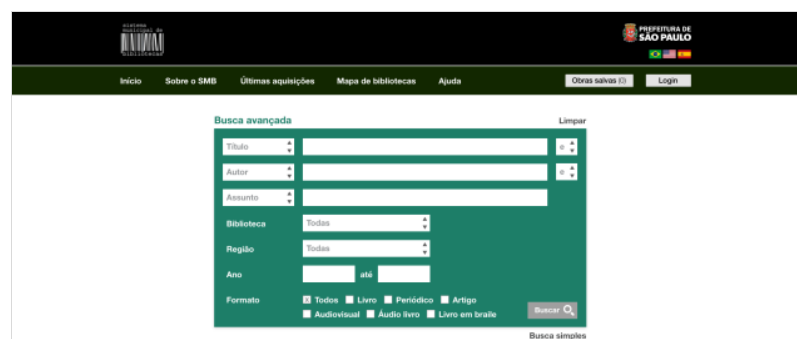

Figura 8: Proposta para tela de busca avançada

Campos de busca com filtro de palavra-chave: título, autor, editora, assunto, ISBN e ISSN. Filtro por biblioteca, região, período de publicação e formato. Foram suprimidas as opções em excesso e separados os botões "Limpar" e "Buscar" no intuito de minimizar erros (Figura 7). Padronizouse o uso do termo busca: "Busca simples", "Busca avançada", "Buscar" (Figura 8).

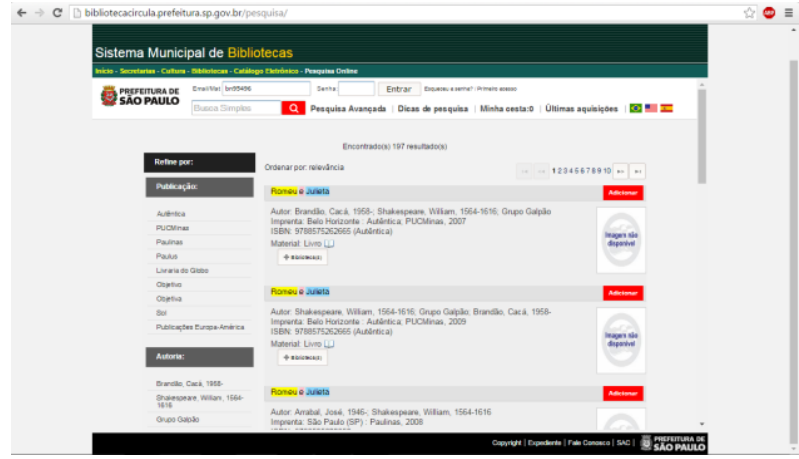

Figura 9: Tela de resultados da busca atual

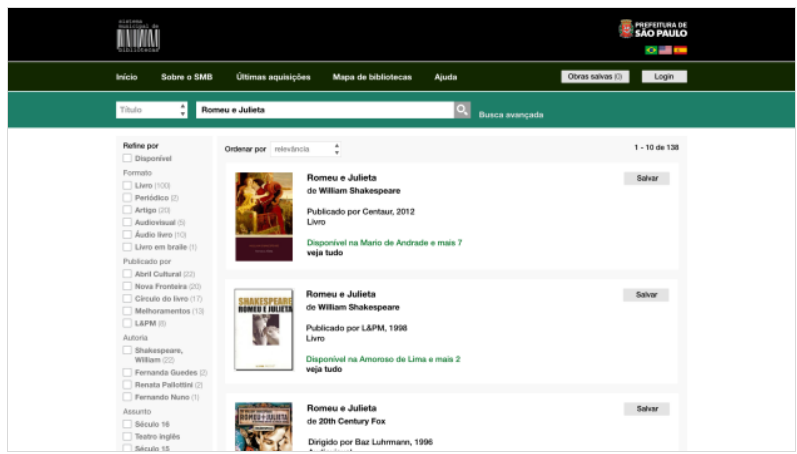

Figura 10: Proposta de tela de resultados da busca

A última busca realizada fica preenchida no campo "Busca simples" (Figura 10) que fica fixado ao topo (estilo Google). Do lado esquerdo, opção para refinar apenas por exemplares disponíveis, 


\section{$16^{\circ}$ \\ ERGODESIGN USIHC CINAHPA}

formato, editora, autor e assunto. Possibilidade de ordenar os resultados por relevância, data de publicação (mais novos) e ordem alfabética. Menos informações sobre os exemplares, apenas título, autor, publicado por, ano, formato e disponibilidade. O botão "+ bibliotecas" foi substituído por "Disponível na BIBLIOTECA e mais X. veja tudo" (Figura 11).

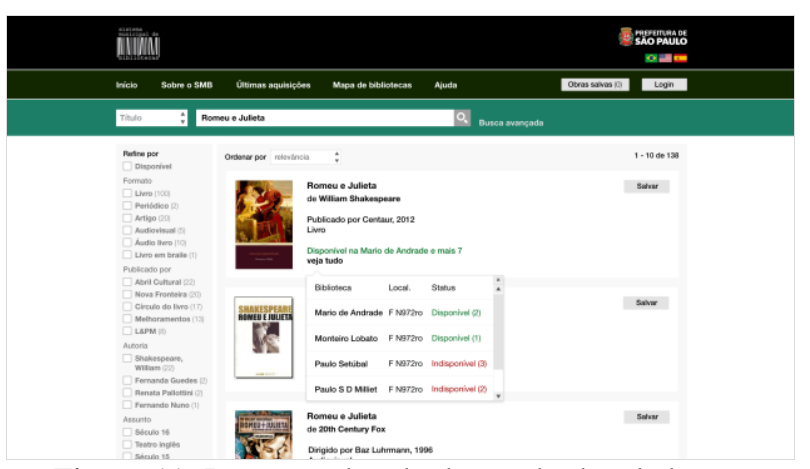

Figura 11: Proposta de tela de resultados da busca - veja tudo

Ao clicar em "veja tudo" (Figura 12) abre um popup com a lista das bibliotecas que possuem o exemplar e a localização do item na estante e o status. O status mostra também a quantidade de exemplares em cada biblioteca. Padronizou-se verde para status disponível, vermelho para indisponível e cinza para consulta.

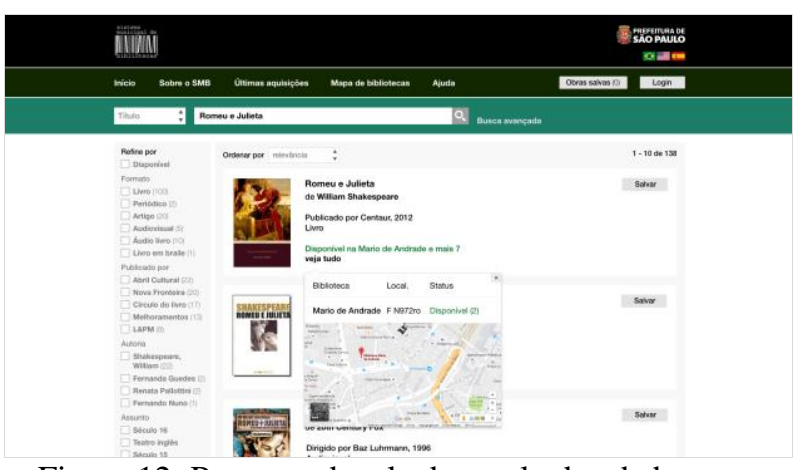

Figura 12: Proposta de tela de resultados da busca veja tudo - mapa

No pop-up "veja tudo", ao clicar no nome da biblioteca, abre um pequeno mapa (Google Maps). A ideia é permitir que o usuário consiga relacionar a biblioteca ao endereço de forma mais rápida.

O protótipo navegável pode ser acessado em: http://adobe.ly/2eeVnRR com todas as telas $16^{\circ}$ Ergodesign - Congresso Internacional de Ergonomia e Usabilidade de Interfaces Humano Tecnológica: Produto, Informações Ambientes Construídos e Transporte

$16^{\circ}$ USIHC - Congresso Internacional de Ergonomia e Usabilidade de Interfaces Humano Computador

CINAHPA | 2017 - Congresso Internacional de Ambientes Hipermídia para Aprendizagem.

propostas. Ao clicar na tela é possível visualizar os botões existentes e fazer a navegação.

\section{Considerações finais}

Acredita-se que os objetivos inicialmente propostos no desenvolvimento do projeto foram atingidos de maneira eficaz. A elaboração do trabalho permitiu a identificação de necessidades e melhorias na plataforma.

Pode-se afirmar que a plataforma de busca do catálogo integrado das bibliotecas que fazem parte do SMB de São Paulo, SP, apesar de cumprir sua função, tem grande potencial para melhoria em termos de experiência do usuário e usabilidade. Chegou-se a essa conclusão com o uso de diferentes métodos e análises aqui apresentados.

Ao elaborar a proposta de melhoria levou-se em consideração o fato de que os usuários que atualmente utilizam este sistema conseguem realizar suas tarefas, ou seja, tem familiaridade com a ferramenta e as possibilidades que ela dá. Também houve preocupação de sugerir a adição de recursos possíveis no software em que o sistema roda atualmente.

Com a realização dos testes com os usuários, foi possível perceber a importância da participação deles e quão diversos podem ser os resultados quando diferentes métodos são aplicados. Desta maneira, espera-se que o estudo realizado, que abrange o trabalho escrito e o protótipo em si, possa contribuir como referência para outros projetos e para a área, além de despertar o interesse para a leitura e a utilização das bibliotecas públicas por cada vez mais usuários.

Por fim, acreditamos na valorização da biblioteca como espaço público de aprendizado, descobertas e desenvolvimento pessoal e coletivo. Com este trabalho, acreditamos que pudemos dar uma pequena contribuição à sociedade através de métodos e técnicas de design e IHC que poderão melhorar a experiência de consulta ao acervo do Sistema Municipal de Bibliotecas de São Paulo.
Realização:
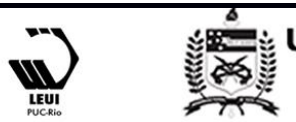


\section{$16^{\circ}$ \\ ERGODESIGN USIHC CINAHPA}

\section{BIBLIOGRAFIA}

ALCÂNTARA, Priscila. Entrevistas. 2013.

Disponível em:

<http://www.slideshare.net/prixvedder/entrevistas23747564>. Acesso em: 13 set. 2016.

KEEFER, Rob. Adapting Information Architecture for Lean and Agile Environments with DoGo Mapping. 2015. Disponível em: $<$ http://uxmag.com/articles/adapting-informationarchitecture-for-lean-and-agile-environments-withdogo-mapping>. Acesso em: 31 ago. 2016.

NIELSEN, Jakob. 10 Usability Heuristics for User Interface Design. 1995. Disponível em: <https://www.nngroup.com/articles/ten-usabilityheuristics/>. Acesso em: 23 ago. 2016.

\section{NIELSEN, Jakob. How to Conduct a Heuristic} Evaluation. 1995. Disponível em: $<$ https://www.nngroup.com/articles/how-toconduct-a-heuristic-evaluation/>. Acesso em: 26 ago. 2016.

NIELSEN, Jakob. Severity Ratings for Usability Problems. 1995. Disponível em: <https://www.nngroup.com/articles/how-to-ratethe-severity-of-usability-problems/> . Acesso em: 26 ago. 2016.

PREECE, Jennifer; ROGERS, Yvone; SHARP, Helen. Design de Interação: Além da integração homem-computador. Porto Alegre: Bookman, 2005. 548 p. Tradução de: Viviane Possamai.

RUBIN, Jeffrey. Handbook of Usability Testing: How to Plan, Design and Conduct Effective Tests. New York: John Wiley \& Sons, Inc., 1994. 330 p.

SISTEMA MUNICIPAL DE BIBLIOTECAS: Quem somos em SMB. 2016. Disponível em: <http://www.prefeitura.sp.gov.br/cidade/secretarias /cultura/bibliotecas/smb/index.php?p=1197>. Acesso em: 13 ago. 2016.

TEIXEIRA, Fabricio. Métodos e entregáveis de UX. Disponível em: <http://fabricio.nu/metodos/>. Acesso em: 11 out. 2016. $16^{\circ}$ Ergodesign - Congresso Internacional de Ergonomia e Usabilidade de Interfaces Humano Tecnológica: Produto, Informações Ambientes Construídos e Transporte

$16^{\circ}$ USIHC - Congresso Internacional de Ergonomia e Usabilidade de Interfaces Humano Computador

CINAHPA | 2017 - Congresso Internacional de Ambientes Hipermídia para Aprendizagem.

UNGER, Russ; CHANDLER, Carolyn. O guia para projetar UX: A experiência do usuário (UX) para projetistas de conteúdo digital, aplicações e web sites. Rio de Janeiro: Alta Books, 2009. 268 p.

ZAWADZKI, Leszek. Introducing the UserCentered Design Canvas. 2016. Disponível em: $<$ https://uxmag.com/articles/introducing-the-usercentered-design-canvas $>$. Acesso em: 14 ago. 2016.
Realização:

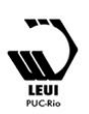

